\title{
MAPEAMENTO DE ÁREAS DE CAMPO LIMPO ÚMIDO NO DISTRITO FEDERAL A PARTIR
} DE FUSÃO DE IMAGENS MULTIESPECTRAIS

\author{
Humid grassland mapping at Distrito Federal, Brazil, using fusion of multispectral images
}

\author{
Andreia Maria da Silva França \\ Mestre em Sensoriamento Remoto, Docente IFB \\ Brasília/DF - Brasil \\ franca.andreiams@gmail.com \\ Edson Eyji Sano \\ Pesquisador da Embrapa Cerrados, Planaltina - DF \\ Planaltina/DF - Brasil \\ sano@cpac.embrapa.br
}

Artigo recebido para publicação em 13/05/2011 e aceito para publicação em 05/07/2011.

RESUMO: As áreas úmidas são cientificamente reconhecidas por seus diversos valores funcionais, entretanto, apesar da importância ecológica destas áreas, são escassos os estudos e conjuntos de dados existentes que incluam informações a respeito da localização e extensão. Nesse contexto, o objetivo do presente trabalho é discriminar e quantificar áreas de Campo Limpo Úmido (CLU) no Distrito Federal por meio de fusão de imagens multiespectrais - Landsat5/TM e CBERS2B/HRC. Imagens de maio a outubro de 2008, da estação seca, foram fusionadas a partir da técnica de processamento IHS. Os resultados mostraram que houve melhora na identificação das áreas de CLU na medida em que permitiu um aumento na discriminação dos alvos já que integrou a maior resolução espacial da banda pancromática à maior resolução espectral das demais bandas. O mapa de distribuição das áreas de CLU indicou um total de aproximadamente $8,46 \mathrm{~km}^{2}$ localizadas essencialmente em unidades de conservação. Conclui-se que a técnica de fusão de imagens, é uma alternativa promissora para a melhor discriminação das áreas de CLU já que esta fitofisionomia do cerrado possui dimensões espaciais reduzidas em relação às fitofissionomias associadas a áreas secas.

Palavras-Chave: Campo Limpo Úmido. Mapeamento. Fusão HIS. Quantificação.

ABSTRACT: Wetlands are among the most important ecosystems on the earth. Despite the importance of these ecosystems, there are few studies and data regarding their location, extent and other basic characteristics. In this study, the mapping of these ecosystems was realized by means of multispectral image fusion Landsat5/TM and CBERS2B/HRC. Images from May to October of 2008 (dry season) were merged by IHS enhancement technique. Results showed that there was an improvement in the identification of areas occupied by humid grasslands since there was an gain in the discrimination of targets once there was an integration of higher spatial resolution of panchromatic band with higher spectral resolution of other bands. The map of distribution of humid grasslands indicated a total of $8,46 \mathrm{~km}^{2}$ located essentially in conservation units.

Keywords: Humid grasslands. Mapping. IHS enhancement technique. Quantify. 


\section{INTRODUÇÃO}

Ainda que o predomínio das fitofisionomias no cerrado sejam as associadas a solos bem drenados, ocorrem neste bioma diferentes fitofisionomias sobre solos periodicamente inundado, correspondendo a ecossistemas de áreas úmidas tais como mata de galeria, veredas e campo úmido (EITEN, 1994; RIBEIRO; WALTER, 1998). Esses ecossistemas, no cerrado, ocorrem em extensas áreas - nas planícies de grandes rios como o rio Araguaia que em conjunto com o rio Javaés forma a planície do Bananal que apresenta campos alagados devido às cheias desses rios - assim como, em áreas restritas em solos temporária ou permanentemente encharcados, devido ao afloramento do lençol freático associado à deficiência de drenagem como no caso dos campos limpos úmidos que ocorrem no Distrito Federal.

Essas áreas são cientificamente reconhecidas por seus diferentes valores funcionais como, por exemplo, a capacidade de manter o regime hídrico dos rios, perenizar os cursos d'água, recarga de águas subterrâneas e armazenar carbono, dentre outras (DUGAN, 1990; YAVITT, 1994; MITRA et al, 2005). Na região do Cerrado, as áreas úmidas são de grande importância não só pelas razões acima expostas, mas também porque na maioria dos casos são sistemas de transição (ecótonos) com ampla conexão de entradas e saídas de matéria e energia em relação aos sistemas adjacentes tais como a atmosfera, os cursos d'água e as formações savânicas e florestais (MEIRELLES et al. 2006).

Apesar da importância destas áreas, são escassos os estudos e conjuntos de dados existentes que incluam informações a respeito da localização, extensão e outras características básicas desses ambientes (MELACK; HESS, 2004). O estudo das áreas úmidas é um desafio, devido à diversidade de tipos/classes, a dinâmica sazonal desses ecossistemas, ocorrência e localização, e principalmente as dificuldades de acesso que limitam o conhecimento sobre tais áreas, o que faz do sensoriamento remoto uma forma viável para sua caracterização e monitoramento (NOVO et al., 1998; BARBOSA et al., 2000). Para este tipo de estudo, a tecnologia de sensoriamento remoto favorece a obtenção de informações sobre amplas áreas e fornece imagens de cobertura global da Terra em crescente qualidade e resolução, possibilitando o monitoramento das variações espaço-temporais das áreas alagáveis (LEHNER; DÖLL, 2004).

Os dados de sensoriamento remoto em várias resoluções temporais, espaciais e espectrais, inclusive com dados disponibilizados gratuitamente, como por exemplo, o sistema sensor HRC (High Resolution Camera) dos satélites sino-brasileiros de recursos terrestres Cbers-2B, assim como, imagens históricas do satélite Landsat5/TM podem fornecer subsídios para responder a questões como: qual a extensão da área úmida; qual o tipo de área úmida; qual o tipo de cobertura da paisagem na área úmida; e se existe vegetação emergente e submergente na área úmida?

É nesse contexto que se insere esse trabalho que tem como principal objetivo discriminar e quantificar áreas de Campo Limpo Úmido no Distrito Federal por meio de fusão de imagens multiespectrais - Landsat5/TM e CBERS2B/HRC.

\section{MATERIAIS E MÉTODOS}

A área de estudo compreende o Distrito Federal do Brasil, que situa-se entre os paralelos $15^{\circ} 30^{\prime}$ e $16^{\circ} 03^{\prime}$ de latitude sul e os meridianos de $47^{\circ} 25^{\prime}$ e $48^{\circ} 12^{\prime}$ de longitude, a oeste de Greenwich (Figura 1). 
Figura 1: Localização da área de estudo.

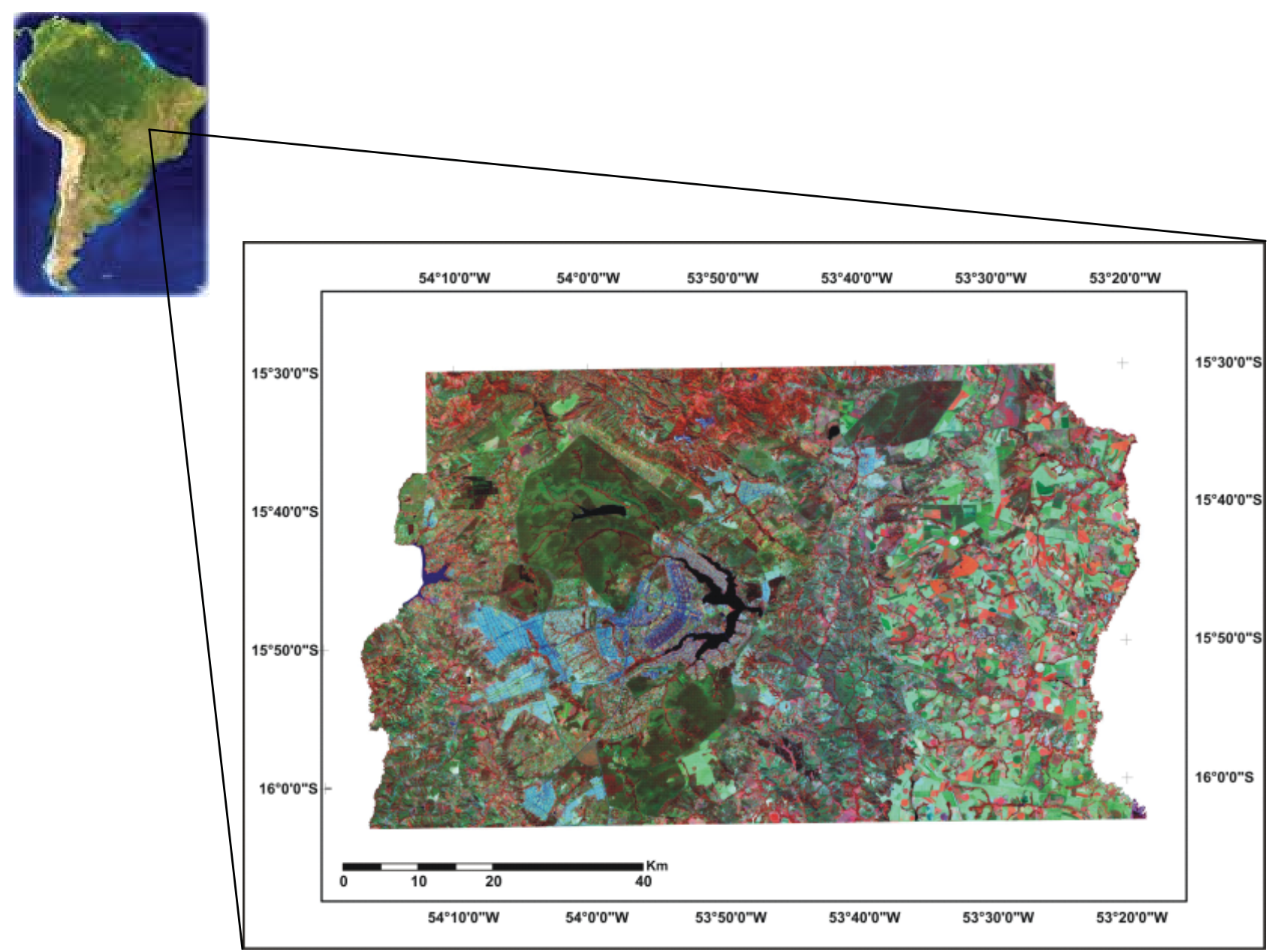

O clima da região, de acordo com a classificação de Koppen, é o Aw, tropical com uma estação seca; a média da diferença entre a temperatura média do mês mais frio e a do mês mais quente é menos de $5{ }^{\circ} \mathrm{C}$ (EITEN, 2001). A média anual das precipitações varia entre $1.200 \mathrm{~mm}$ a $1.700 \mathrm{~mm}$, entretanto, a média dos últimos anos apresenta uma variação em torno de $1.200 \mathrm{~mm}$ a $1.400 \mathrm{~mm}$. O período mais chuvoso corresponde aos meses de novembro a janeiro. A estação seca dura cerca de 5 meses, geralmente do meio de maio até meados de setembro.

O Distrito Federal foi selecionado como limite para o mapeamento das áreas de Campos Limpos Úmidos tendo em vista: 1) facilidade de acesso para validação de mapeamento; 2) a presença de áreas de Campo Limpo Úmido em unidades de conservação de relevante interesse para a preservação do Bioma
Cerrado; 3) são áreas úmidas preservadas; e 4) representatividade quanto aos solos predominantes em áreas úmidas, ou seja, Plintossolos e Gleissolos.

Para a realização desta pesquisa, foram utilizadas cenas do satélite Cbers2B/HRC e Landsat5/TM correspondentes à época seca. As características das imagens estão apresentadas na Tabela 1 . Na construção do banco de dados geográficos e processamento das imagens, foi utilizado o SPRING 4.2 (Sistema de Processamento de Informações Georeferenciadas). Já para a edição vetorial e consequentemente o mapeamento das áreas úmidas, foi utilizado o ArcMap 9.3. Essas imagens foram georreferenciadas para o sistema de projeção UTM e datum WGS/84 e posteriormente foram recortadas segundo o limite físico do Distrito Federal. 
Mapeamento de áreas de Campo Limpo Úmido no Distrito Federal a partir de fusão de imagens multiespectrais Andreia Maria da Silva França, Edson Eyji Sano

Tabela 1: Datas de passagem e época das imagens da área de estudo.

\begin{tabular}{|c|c|c|c|c|}
\hline Satélite/Sensor & Órbita/Ponto & Data de Passagem & $\begin{array}{l}\text { Nível do lençol } \\
\text { freático }\end{array}$ & Época \\
\hline LANDSAT-5/TM & $221 / 71$ & $28 / 05 / 2008$ & Acima superfície & Seca \\
\hline \multirow{3}{*}{ CBERS-2B/HRC } & $157 \mathrm{~A} / 117 \quad 5$ & \multirow{3}{*}{$13 / 10 / 2008$} & \multirow{3}{*}{ Abaixo superfície } & \multirow{3}{*}{ Seca } \\
\hline & $157 \mathrm{~A} / 118$ & & & \\
\hline & $157 \mathrm{~A} / 1182$ & & & \\
\hline \multirow{3}{*}{ CBERS-2B/HRC } & $157 \_\mathrm{B} / 117 \_5$ & \multirow{3}{*}{ 05/06/2008 } & \multirow{3}{*}{ Acima superfície } & \multirow{3}{*}{ Seca } \\
\hline & $157 \_\mathrm{B} / 118 \_1$ & & & \\
\hline & $157 \_\mathrm{B} / 118 \_2$ & & & \\
\hline \multirow{2}{*}{ CBERS-2B/HRC } & 157_C/117_5 & \multirow{2}{*}{$22 / 08 / 2008$} & \multirow{2}{*}{ Abaixo superficie } & \multirow{2}{*}{ Seca } \\
\hline & 157_C/118_2 & & & \\
\hline CBERS-2B/HRC & $157 \mathrm{D} / 118 \_1$ & $27 / 07 / 2008$ & Acima superfície & Seca \\
\hline
\end{tabular}

Os procedimentos metodológicos na área de sensoriamento remoto compreenderam as seguintes etapas: (1) seleção de imagens em diferentes resoluções; (2) restauração das imagens Landsat5/TM; (3) registro das imagens TM e HRC; (4) fusão IHS; (5) recorte; (6) segmentação; (7) classificação; (8) edição vetorial; e (9) análise da exatidão de mapeamento.

As imagens Landsat5/TM e Cbers2B/HRC foram selecionadas principalmente devido à possibilidade de integração de dados gratuitos que fusionados fornecem informações de alta resolução espacial, característica essencial para o mapeamento de áreas úmidas. As imagens foram referentes à época seca devido principalmente a pouca cobertura de nuvens. As imagens estão disponíveis gratuitamente no endereço eletrônico < http://www.dgi.inpe.br/CDSR/>.

As imagens LANDSAT5/TM foram restauradas para amenizar a diferença de resolução espacial a imagem TM e HRC, para isso o software SPRING 4.2 foi utilizado. As bandas TM têm resolução espacial de 30 metros enquanto a imagem HRC tem resolução de 2,5 metros. O resultado da fusão IHS para as imagens desses sensores obteve um melhor resultado utilizando a restauração das imagens TM com resolução espacial de 10 metros, ao invés da resolução original.

A restauração é uma técnica de correção radiométrica cujo objetivo é corrigir as distorções inseridas pelo sensor óptico no processo de geração das imagens digitais (FONSECA, 1988). A restauração da imagem reduz o efeito de borramento e, portanto obtêm uma imagem realçada. A correção é realizada por um filtro linear. Os pesos do filtro de restauração são obtidos a partir das características do sensor, e não de forma empírica como é feito no caso dos filtros de realce tradicionais. Neste caso, o filtro é específico para cada tipo de sensor e banda espectral (FONSECA, 1988).

As imagens Landsat5/TM e Cbers2B/HRC foram georreferenciadas utilizando o SPRING 4.2, com base em cenas Landsat7/ETM ${ }^{+}$Geocover do GLCF (Global Landsat Cover Facility) referentes ao ano 2000. Estas cenas foram adquiridas gratuitamente pelo endereço eletrônico <http://www.glcf.umd.edu/

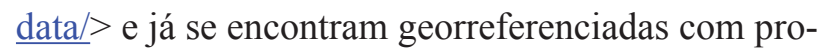
jeção UTM/WGS84. O Geocover é um mosaico de imagens Landsat que foram ortorretificadas e processadas com um alto padrão de qualidade e comumente são adotadas para a execução do georreferenciamento.

$\mathrm{O}$ procedimento de registro de imagens com base em cenas Landsat $7 / \mathrm{ETM}^{+}$Geocover é feito através da coleta de pontos de controle correspondentes entre elas. Desses se conhece as coordenadas atuais na imagem a ser registrada e as coordenadas que deverão ter, conforme a cena Landsat $7 / \mathrm{ETM}^{+}$Geocover. A partir dos pontos de controle, o programa vai definir através de uma equação, um ângulo de rotação da imagem a ser registrada, para que corresponda o máximo possível com a imagem base. A precisão de georreferenciamento das imagens foi superior 0,5 pixels e foram utilizados de 7 a 15 pontos de controle.

Após o georreferenciamento, foi aplicada nas imagens a técnica de fusão IHS que foi realizada utilizando o SPRING 4.2. Este processamento permitiu 
integrar a maior resolução espacial da banda pancromática à maior resolução espectral das demais bandas, produzindo uma composição colorida da imagem que reúne ambas as características.

Esse processamento utiliza os conceitos de Hue (H), Saturation (S) e Intensity (I) para explicar a idéia de cor. A intensidade (Intensity) é a medida da energia total presente em todos os comprimentos de onda, sendo responsável pela sensação de brilho; o matiz (Hue) de um objeto é a medida do comprimento de onda médio da luz que ele reflete ou emite, responsável pela definição da cor do objeto; e a saturação
(Saturation) é o grau de pureza da cor; pode ser considerado como a proporção de branco misturado com a cor. A cor pura é 100\% saturada (CRÓSTA, 1992).

A transformação IHS é feita em múltiplas etapas. Primeiramente, nas três bandas selecionadas, o programa faz a transformação para IHS, representando intensidade, matiz e saturação do triplete original. A seguir, aplica-se um aumento linear de contraste e faz-se a reversão das três imagens para o espaço RGB (CRÓSTA, 1992). Os procedimentos e o resultado da fusão IHS entre os sensores TM e HRC está representado na Figura 2.

Figura 2: Procedimento de fusão de três bandas de imagem CCD com HRC.

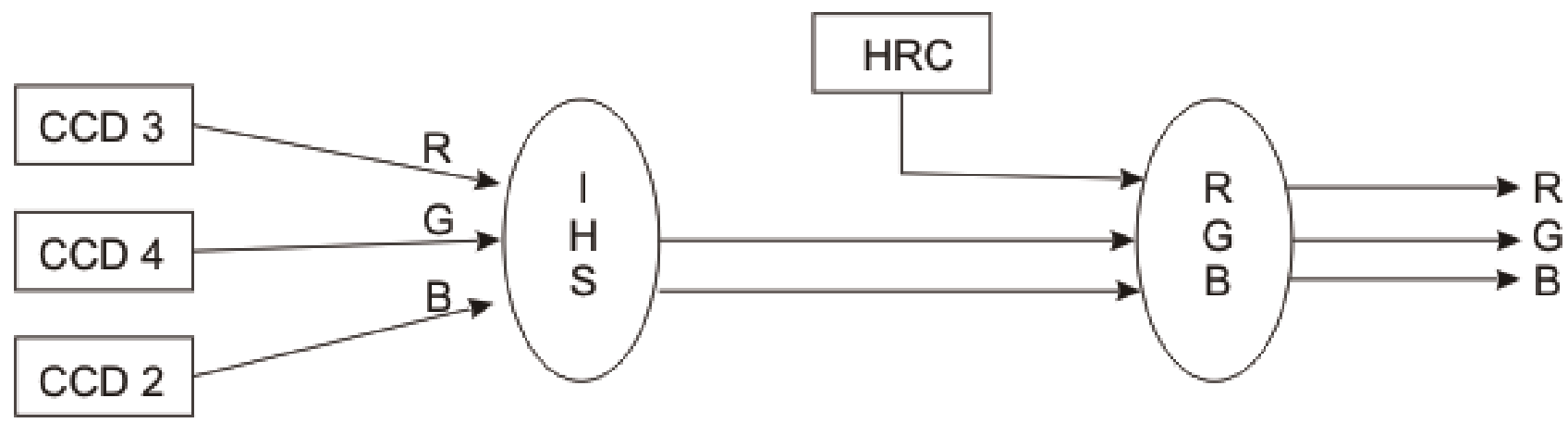

Com o objetivo de otimizar o tempo de processamento, as imagens fusionadas foram recortadas. $\mathrm{Na}$ área de estudo, os Campos Limpos são encontrados com frequência circundando as Veredas e na borda das Florestas de Galeria, portanto foi gerado um "buffer" de $500 \mathrm{~m}$, ao longo dos cursos d'água. Esse "buffer" foi criado a partir da rede de drenagem do Distrito Federal na escala de 1:50.000, importada para o banco de dados.

As imagens recortadas foram segmentadas a partir da técnica de segmentação de imagens por crescimento de regiões, disponível no aplicativo SPRING 4.2 (CÂMARA et al., 1996). Este método foi aplicado com o objetivo de compor segmentos específicos para as áreas de Campo Limpo Úmido, separando-as das fitofissionomias associados a solos bem drenados, como as áreas de Campo Limpo. A técnica por crescimento de regiões é um processo interativo pelo qual os pixels vão sendo agrupados segundo algum critério de similaridade, formando regiões (BINS et al., 1996).

Para iniciar este processo, o usuário deve fornecer dois limiares: similaridade e área mínima. A similaridade define a diferença mínima entre o valor de um pixel e o valor médio da região contígua a ele, para que este pixel possa ser agrupado a esta região. Se a diferença entre o valor de pixel e a média da região vizinha for maior que o valor de similaridade definida pelo usuário, o pixel não será agrupado àquela região. A área mínima define o menor tamanho de região permitida pelo usuário, ou seja, não haverá regiões com área em pixel menor do que o valor definido pelo usuário (BARBOSA et al., 2000). Não existem valores ideais de similaridade e área, pois dependem basicamente: (1) características dos dados de sensores; (2) data da coleta dos dados; (3) características da área de estudo e (4) parâmetros de processamento de imagens definidos. Nesta pesquisa, foram realizados vários testes, o melhor resultado obteve valores de similaridade e área mínima iguais a 20 e 30, respectivamente.

Após a segmentação, foi realizada a classificação das imagens fusionadas. A classificação não supervisionada, na qual o algoritmo de classificação avalia em qual classe alocar cada região em função 
de seus atributos estatísticos, de média, matriz de covariância, e também pela área foi utilizado devido: (1) à grande variabilidade de ambientes; (2) tipos de cobertura vegetal e (3) insuficiência de dados de campo. A técnica utilizada nesta pesquisa foi a ISOSEG, disponível no aplicativo Spring.

Neste tipo de classificação o usuário faz uma identificação a posteriori das classes resultantes. Uma análise visual das imagens originais, do resultado de classificação e de informações adicionais disponíveis para algumas áreas, permite esta identificação (BARBOSA et al., 2000).

O classificador ISOSEG é um algoritmo que procura agrupar regiões, a partir de uma medida de similaridade entre elas e utiliza os atributos estatísticos das regiões, a matriz de covariância e o vetor de média, para estimar o valor central de cada classe (BINS et al. 1996). A medida de similaridade utilizada consiste na distância de Mahalanobis entre a classe e as regiões candidatas à relação de pertinência com esta classe. Para maiores informações a respeito deste algoritmo o leitor poderá consultar BINS et al. (1996).

Os polígonos gerados pela classificação das imagens foram convertidos para o formato shape e exportados para o aplicativo Arc GIS 9.3 ${ }^{\mathrm{TM}}$. Esse procedimento foi realizado para subsidiar a edição vetorial objetivando a correção dos erros do mapeamento, resultantes da aplicação da técnica de classificação automática adotada. A rotulação de classes de Campo Limpo Úmido e Campo Limpo Seco de cada polígono foi feita diretamente no monitor da tela de computador, sobrepondo-se a composição colorida das imagens fusionadas com o mapa vetorial da classificação em uma escala de visualização de aproximadamente 1:50.000. Para subsidiar a interpretação de imagens, foram considerados os elementos espectrais (cores), texturais e padrões geométricos, assim como, por dados de campo e imagens de alta resolução disponíveis no programa Google Earth ${ }^{\circledR}$.

A última etapa desse estudo foi a análise da exatidão de mapeamento, conduzida com base na verificação em campo de 28 pontos de amostragem. Para aferir a qualidade do mapeamento, foram realizados trabalhos de campo onde foram selecionados 28 pontos de forma aleatória, porém, próximos às principais rodovias para melhor acesso. As campanhas ocorreram nos dias 15 e 26 de março de 2011. A exatidão de mapeamento fornece a confiabilidade do mapa temático confeccionado. Uma matriz de erro (Figura 3), também denominada matriz de confusão ou tabela de contingência, pode ser usada como o ponto de partida para a aplicação de uma série de técnicas estatísticas descritivas e analíticas. Nessa pesquisa, para medir a acurácia de mapeamento, foi utilizado o índice Kappa.

Figura 3: Matriz de erro usada para a aplicação de técnicas estatísticas descritivas como, por exemplo, o índice de exatidão global.

\section{Classificação}

\begin{tabular}{|c|c|c|c|c|c|}
\hline & 1 & 2 & $\ldots$ & $c$ & Total \\
\hline 1 & $x_{1}$ & $x_{12}$ & $\ldots$ & $x_{1 \mathrm{c}}$ & $x_{1+}$ \\
\hline 2 & $x_{21}$ & & $\ldots$ & $x_{2 c}$ & $x_{2+}$ \\
\hline$\vdots$ & $\vdots$ & $\vdots$ & & $\vdots$ & $\vdots$ \\
\hline$c$ & $x_{\mathrm{cl}}$ & $x_{\mathrm{c} 2}$ & $\cdots$ & $x_{0}$ & $x_{\mathrm{c}+}$ \\
\hline Total & $x_{+1}$ & $x_{+2}$ & $\cdots$ & $x_{+c}$ & $n$ \\
\hline
\end{tabular}

Segundo Lillesand et al.(2004) a matriz de erro, compara basicamente, classe por classe, a relação entre os dados de referência conhecidos e os resultados correspondentes de uma classificação automatizada.
Chuvieco (1990) explicou que os dados de referência podem ser obtidos a partir de trabalhos de campo ou de documentos auxiliares, como fotografias aéreas e cartas. 
Em uma análise mais rigorosa, devem-se levar em consideração os valores nas células marginais da matriz. No caso das linhas, os valores indicam o número de amostras que, pertencendo a uma determinada categoria, não foram incluídos nela. A estimativa Kappa expressa à medida da diferença entre a concordância dos dados de referência e a classificação automática, e a probabilidade de concordância entre os dados de referência e a classificação aleatória, sendo expressa por:

$\mathrm{K}=\frac{\theta 1-\theta 2}{1-\theta 2} \frac{\theta 1-\theta 2}{1-\theta 2}$

Onde:

$\theta_{1}=$ observado, ou seja, soma dos acertos/total ponto $\theta_{2}=$ esperado, ou seja, soma da diagonal dos produtos totais marginais/soma dos totais marginais.

\section{RESULTADOS E DISCUSSÕES}

Segundo Ribeiro e Walter (1998) os Campos Limpos apresentam variações dependentes de particularidades ambientais, determinadas pela umidade do solo e topografia. O Campo Limpo é uma fitofisionomia que apresenta predominantemente uma camada rasteira dominada por gramínea, com raros arbustos.

Os Campos Limpos Úmidos, portanto, se traduzem como fisionomias campestres, dominado por graminóides, sem camada lenhosa, entretanto, se estabelecem em solos temporária ou permanentemente encharcados, devido ao afloramento do lençol freático associado à deficiência de drenagem (Figura 4) (EITEN, 1994; RATTER et al., 1997; RIBEIRO; WALTER, 1998; EITEN, 2001).

Figura 4: Campo Limpo Úmido durante a época seca (a) e durante a época úmida (b).

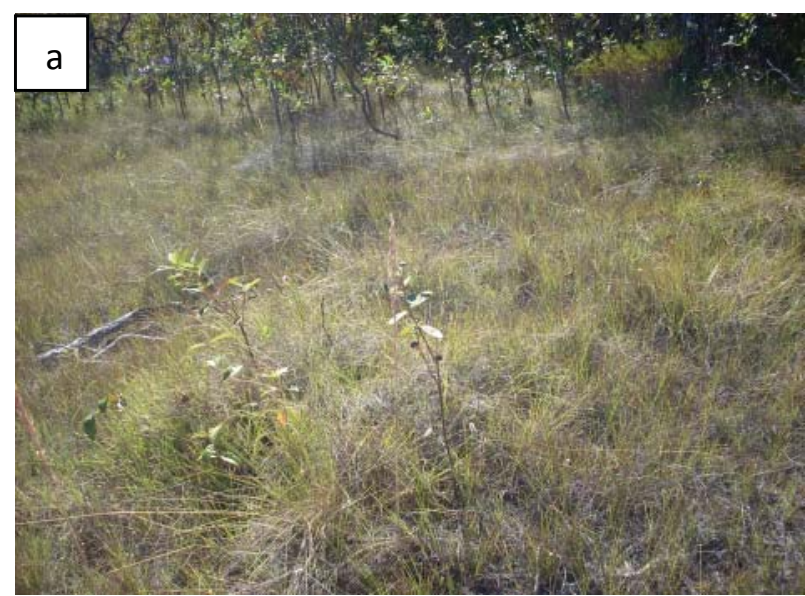

As áreas de Campo Limpo Úmido possuem dimensões espaciais reduzidas em relação às fitofisionomias associadas a áreas secas. In loco, os Campos Limpos Úmidos possuem um limite definido entre o Cerrado sensu stricto e a Floresta de Galeria, sendo, quase sempre, bem nítido de maneira que uma pessoa pode ficar com um pé no campo puro e o outro pé dentro da Floresta de Galeria (EITEN, 2001).

As Figuras 5a e 5b ilustram as imagens utilizadas para a realização da fusão pelo método IHS, e a Figura $5 \mathrm{c}$ apresenta o resultado da imagem fusionada. Pode-se observar que a imagem fusionada apresenta

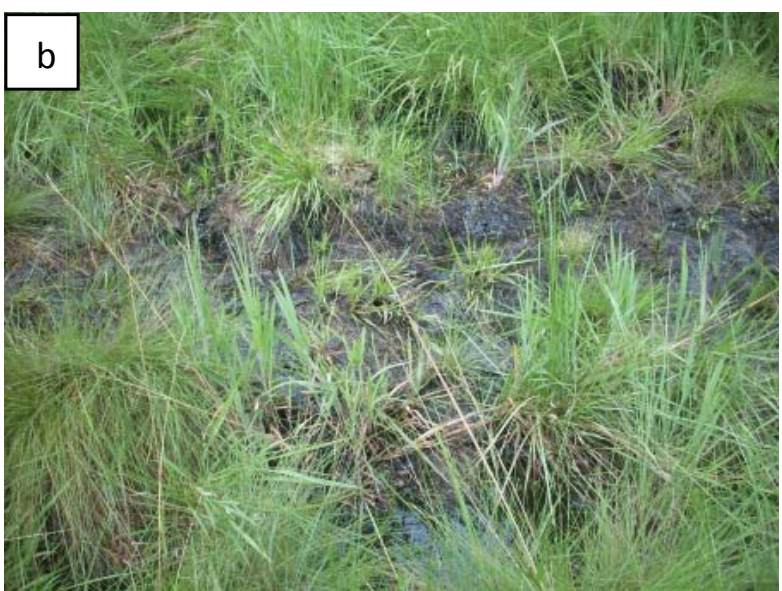

uma riqueza de detalhes, pois integra a resolução espacial da banda pancromática com a resolução espectral das bandas espectrais. Esta característica foi um dos determinantes no momento de discriminar as áreas de Campo Limpo Úmido, pois a imagem fusionada, a partir do método IHS, ocasionou uma observação com grande detalhamento dos objetos da superfície, característica importante para estudos dessa natureza, pois a estimativa adequada da extensão, sazonalidade e tipos de cobertura vegetal destas áreas necessita de imageamento em grandes escalas. 
Figura 5: (a) Imagem Landsat/TM; (b) Imagem HRC; (c) Fusão de três bandas de imagem TM com HRC, área localizada na Estação Ecológica de Águas Emendadas - Brasília/DF.

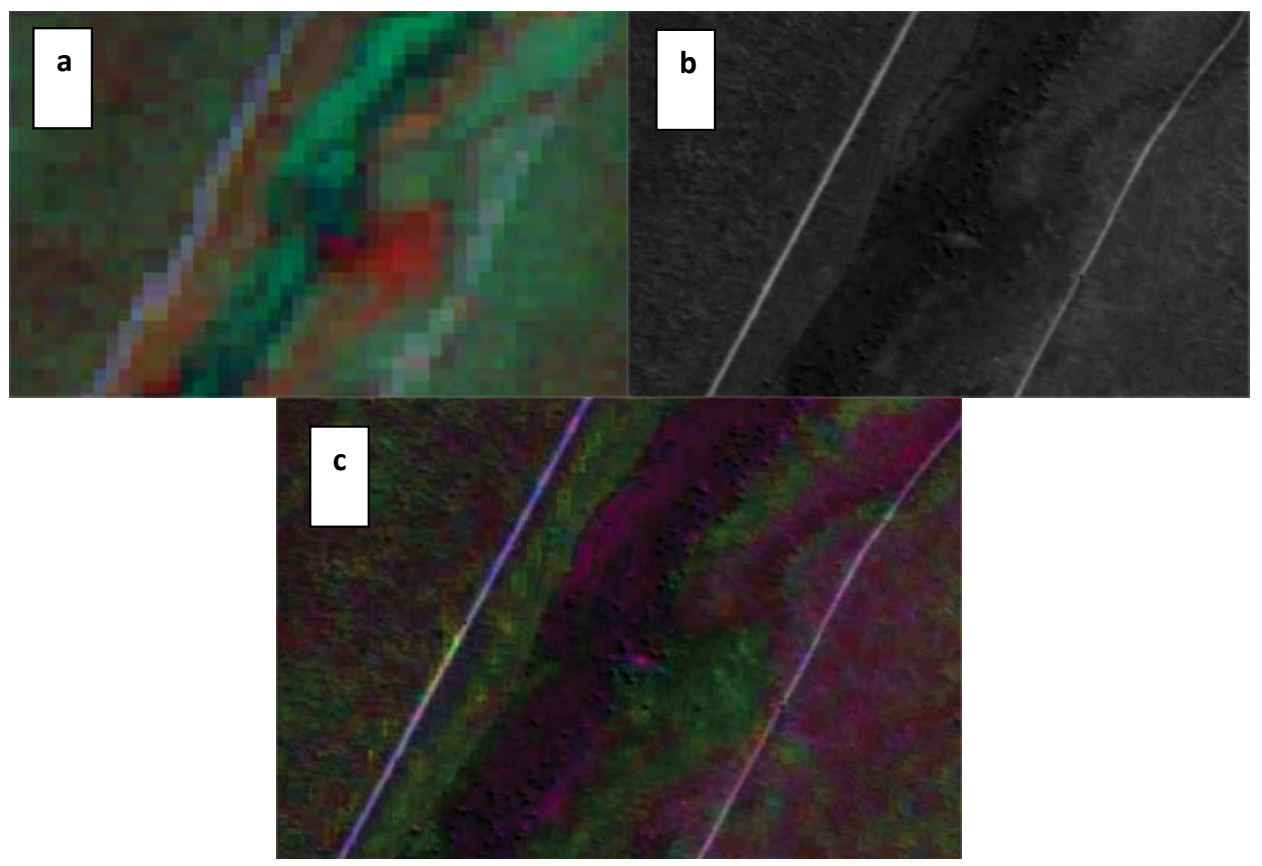

As imagens fusionadas da área de estudo, foram recortadas utilizando o buffer produzido e descrito na metodologia (Figura 6). O uso dessa máscara permitiu suprimir as fitofisionomias de áreas secas e outros tipos de classes que não são de interesse dessa pesquisa como, por exemplo, áreas urbanas. Esse processamento permitiu otimizar o tempo de segmentação e determinação de parâmetros adequados para a segmentação das imagens com objetivo de mapear as áreas de Campo Limpo Úmido.

Figura 6: (a) Fusão de três bandas de imagem TM com HRC; (b) Máscara gerada utilizando o "buffer" criado a partir da rede de drenagem do Distrito Federal; (c) Imagem fusão recortada.

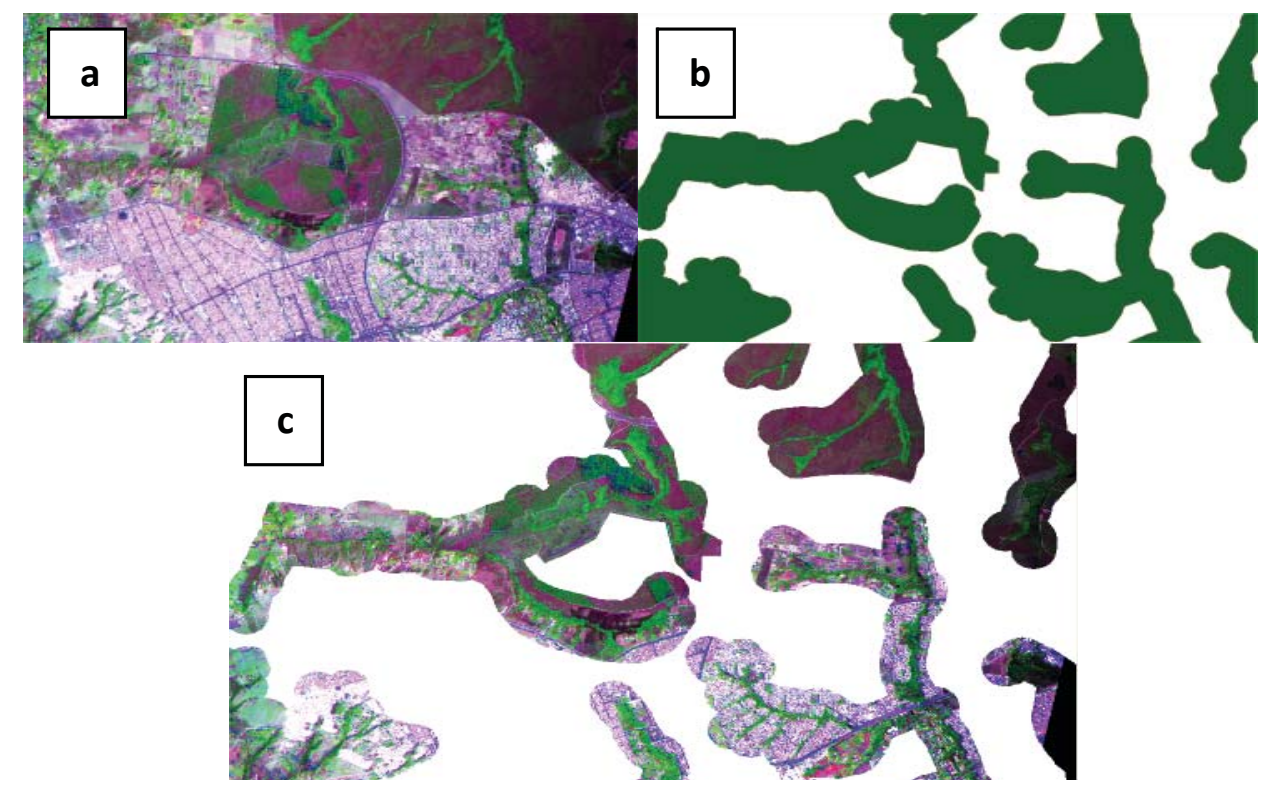

Soc. \& Nat., Uberlândia, ano 23 n. 2, 197-209, maio/ago. 2011 
De posse das imagens fusionadas e recortadas, foram realizados vários testes de segmentação. Para a delimitação das áreas de Campo Limpo Úmido, o limiar e similaridade mais adequados foram 20 e 30, respectivamente. Estes limiares permitiram seccionar mais a imagem, o que possibilitou uma melhor delimitação das áreas de Campo Limpo Úmido, que possuem áreas em média menores que $1,5 \mathrm{~km}^{2}$.

Após a execução do processo de segmentação, efetuou-se a classificação da imagem. O classificador ISOSEG é um dos algoritmos disponíveis no SPRING para classificar regiões de uma imagem segmentada. Dos vários testes de limiares aplicados na classificação das imagens da área de estudo, optou-se pelo uso do limiar de aceitação $95 \%$ considerado o mais adequado para os objetivos deste trabalho.

As áreas de Campo Limpo Úmido ocorrem associadas a veredas que possuem dimensões espaciais limitadas e em alguns casos do total destes ambientes preservam-se apenas alguns indivíduos de buriti (Mauritia flexuosa), tornando difícil a individualização dessas duas fitofisionomias - Campo Limpo Úmido e
Vereda - por sensoriamento remoto, mesmo utilizando imagens com alta resolução espacial. Portanto, nesta pesquisa as áreas de Campo Limpo Úmido são consideradas em conjunto com as de Veredas. As classes de Campo Limpo Seco e Campo Limpo Úmido possuem características de resposta espectral similar e influenciaram os algoritmos de classificação, não produzindo, portanto, um bom resultado na delimitação das áreas de Campo Limpo Úmido.

A conversão da imagem classificada para o formato shape e consequentemente a sua exportação para o aplicativo Arc GIS 9.3 ${ }^{\mathrm{TM}}$, permitiu a correção dos erros do mapeamento, resultantes da aplicação da técnica de processamento automático adotado. $\mathrm{O}$ mapeamento em si, ou seja, a identificação dos alvos de interesse foi realizado diretamente no monitor da tela de computador, sobrepondo-se a composição colorida da imagem fusão com o mapa vetorial de segmentação. Para subsidiar a análise/interpretação das imagens, foi definida uma chave de interpretação em que foram considerados os elementos espectrais (cores), texturais e forma (Tabela 2).

Tabela 2: Exemplo de chave de interpretação utilizada para mapeamento de Campo Limpo Úmido e Campo Limpo.

\begin{tabular}{|c|c|c|}
\hline Classe & $\begin{array}{l}\text { Padrões Característicos de Interpre- } \\
\text { tação }\end{array}$ & Composição Colorida \\
\hline Campo Limpo Úmido & $\begin{array}{l}\text { Cor: magenta } \\
\text { Textura: lisa } \\
\text { Forma: irregular }\end{array}$ & \\
\hline Campo Limpo & $\begin{array}{c}\text { Cor: magenta a vermelho claro } \\
\text { Textura: intermediária } \\
\text { Forma: irregular }\end{array}$ & \\
\hline
\end{tabular}

A partir da análise do mapa elaborado (Figura 7) e da quantificação da classe Campo Limpo Úmido mapeada, foi possível observar que 847 hectares do Distrito Federal são cobertos por essa fitofisionomia. 


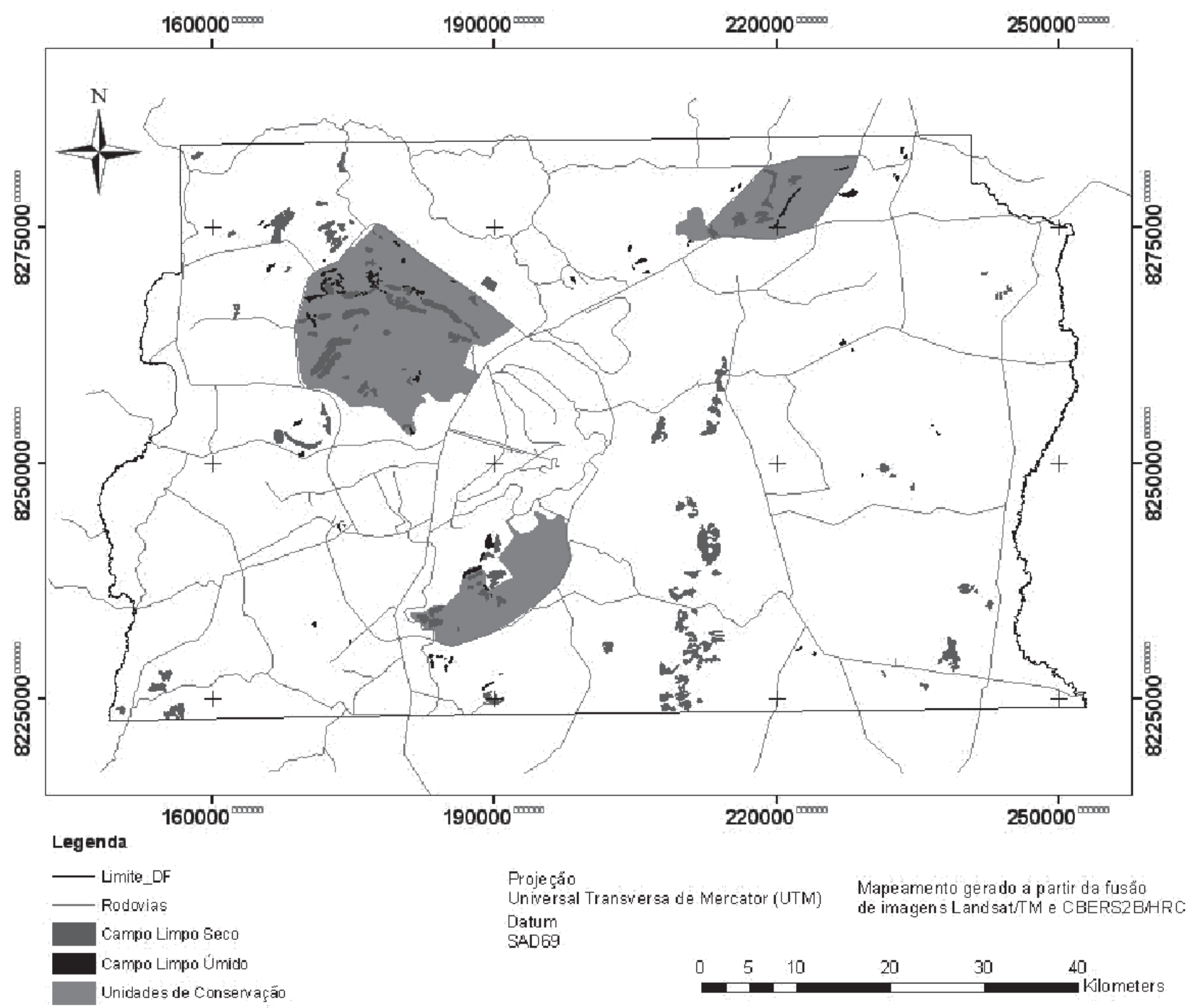

Do conjunto de 28 pontos verificados em campo (Tabela 3), 25 foram mapeados corretamente, obtendo um índice de mapeamento global de $89,28 \%$. Baseado apenas neste resultado, poderia se concluir que este índice foi excelente. No entanto, Congalton (1991) alertou que, com base apenas no índice de exatidão global, as inferências feitas podem gerar equívocos. Segundo Brites et al. (1996), a exatidão global apresenta maiores valores em relação aos demais índices, pelo fato de considerar apenas a dia- gonal principal da matriz de contingência, ignorando a ocorrência de concordância casual entre as classes. Por outro lado, o coeficiente Kappa, é considerado mais consistente que a exatidão global por envolver, no índice final, todas as células da matriz de confusão. Nas Tabelas 3 e 4 estão dispostos os valores da matriz de confusão, gerada pela verificação em campo e pela imagem classificada, a partir dos quais foi obtido o índice Kappa. 
Tabela 3: Classificação visual x verdade de campo. Campo Limpo Úmido = CLU; e CLS = Campo Limpo Seco.

\begin{tabular}{|c|c|c|c|c|}
\hline & & \multicolumn{3}{|c|}{ Classificação } \\
\hline & & CLU & CLS & TOTAL \\
\hline \multirow{3}{*}{$\begin{array}{c}\text { Verdade } \\
\text { de Campo }\end{array}$} & CLU & 10 & 2 & 12 \\
\hline & CLS & 1 & 15 & 16 \\
\hline & TOTAL & 11 & 17 & 28 \\
\hline
\end{tabular}

Tabela 4: Matriz de erros de mapeamento de CLU do DF.

\begin{tabular}{|c|c|c|c|c|}
\hline & & \multirow{2}{*}{\multicolumn{3}{|c|}{ Classificação }} \\
\hline & & & & \\
\hline & & CLU & CLS & TOTAL \\
\hline \multirow{3}{*}{$\begin{array}{c}\text { Verdade } \\
\text { de Campo }\end{array}$} & CLU & 132 & 204 & 336 \\
\hline & CLS & 176 & 272 & 448 \\
\hline & TOTAL & 308 & 476 & 784 \\
\hline
\end{tabular}

O conjunto de pontos verificados obteve um índice de Kappa de aproximadamente $78 \%$. Esse valor, determinado através da Eq. 1, é comparado aos valores contidos na Tabela 5, desenvolvida por Landis e Koch (1977). Observando os valores da Tabela 5, conclui-se que a qualidade do mapa temático foi muito boa.

$$
\mathrm{K}=\frac{\theta 1-\theta 2}{1-\theta 2} \frac{\theta 1-\theta 2}{1-\theta 2}
$$

Onde:

$\theta_{1}=$ observado $=$ soma dos acertos $/$ total ponto $=$ $25 / 28=0,8928$ ou $89 \%$

$\theta_{2}=$ esperado $=$ soma da diagonal dos produtos totais marginais/soma dos totais marginais $=$ $404 / 784=0,5153$

$$
K=\frac{0,89-0,51}{1-0,51}=0,7789
$$

Tabela 5: Qualidade da classificação associada aos valores da estatística Kappa.

\begin{tabular}{c|c}
\hline Valor de Kappa & Qualidade do mapa temático \\
\hline$<0,00$ & Péssima \\
\hline $0,00-0,20$ & Ruim \\
\hline $0,20-0,40$ & Razoável \\
\hline $0,40-0,60$ & Boa \\
\hline $0,60-0,80$ & Muito Boa \\
\hline $0,80-100$ & Excelente \\
\hline
\end{tabular}

Adaptada de Landis e Koch (1977). 


\section{CONCLUSÕES}

As imagens Landsat5/TM e Cbers2B/HRC, fusionadas a partir da técnica de processamento IHS, mostraram-se eficientes para a discriminação e quantificação das áreas de Campo Limpo Úmido do Distrito Federal.

Os resultados mostraram que houve melhora na identificação das áreas de Campo Limpo Úmido na medida em que o processamento IHS permitiu um aumento na discriminação dos alvos, pois integrou a maior resolução espacial da banda pancromática à maior resolução espectral das demais bandas multiespectrais. O mapa de distribuição das áreas de CLU indicou um total de aproximadamente $8,46 \mathrm{~km}^{2}$ localizadas essencialmente em unidades de conservação.

Conclui-se que a técnica de fusão de imagens IHS é uma alternativa promissora para a melhor discriminação das áreas de Campo Limpo Úmido já que esta fitofisionomia do Cerrado possui dimensões espaciais reduzidas em relação às fitofissionomias associadas a áreas secas o que dá um grande potencial para as imagens de alta resolução espacial. Uma possível limitação no emprego dessas imagens é a quantificação da área total de abrangência das áreas úmidas no Cerrado devido à grande extensão desse bioma - mais de 2 milhões de km² .

\section{REFERÊNCIAS}

BARBOSA, C.; HESS, L.; MELACK, J.; NOVO, E. M. L. M. Mapping Amazon basin wetlands through region growing segmentation and segmentedbased classification JERS-1 data.

Anais... IX Simpósio Latino Americano de Percepcion Remota y Sistemas de Informacion Espacial. 2000. p. 1165-1176.

BINS, L. S.; FONSECA, L. M. G.; ERTHAL, G. J.; Mitsuo II, F. Satellite imagery segmentation: a region growing approach. Anais... VII Simposio Brasileiro de Sensoriamento Remoto. Salvador. Brasil, 1996.

BRITES, R. S.; SOARES, V. P.; RIBEIRO, C. A. A. S. Verificação da exatidão em classificações de uma imagem orbital mediante a utilização de três índices. Revista Árvore, v. 20, p.415-424, 1996.
CÂMARA, G.; MEDEIROS, J. S. Geoprocessamento para projetos ambientais. In: CÂMARA, G.; BARBOSA, C. C. F.; FREITAS, U. M. (Eds.). Operações de Análise Geográfica. São José dos Campos: INPE, 1998. Disponível em: http://www.dpi.inpe.br/gilberto/ tutoriais/gis_ambiente/3opera.pdf Acesso em: 20 ago. 2011.

CHUVIECO, E. Fundamentos de Teledection Espacial. Madrid: Unigraf, 1990. 453p.

CONGALTON, R. G. A review of assessing the accuracy classifications of remotely sensed data. Remote Sensing Environmen. v. 37, p. 35-46, 1991.

CRÓSTA, A. P. Processamento Digital de Imagens de Sensoriamento Remoto. Campinas, UNICAMP. 1992. $170 \mathrm{p}$.

DUGAN, P. Wetland Conservation. IUCN, 1990.95 p.

EITEN, G. Vegetação do Cerrado. In: Pinto, M. N. (Ed.). Cerrado. SEMATEC, Brasília/DF. 1994. p. 17-76.

. Vegetação Natural do Distrito Federal. Ed. UnB. SEBRAE/DF, Brasilia, DF. 2001.

FONSECA, L. M. G. Restauração de imagens do satélite Landsat por meio de técnicas de projeto de filtros FIR. 1988. 148f. Dissertação (Mestrado em Engenharia Eletrônica) - Instituto Tecnológico de Aeronáutica, São José dos Campos, 1988.

GLCF. Global Land Cover Facility. Landsat Geocover. Disponível em: <http://www.glcf.umd.edu/ data/>Acesso em: 15 Jun. 2009.

INPE. Instituto Nacional de Pesquisas Espaciais. Catálogo de imagens. Disponível em: $<$ http://www.dgi. inpe.br/CDSR/> Acesso em: 20 Jun. 2009.

LANDIS, J. R.; KOCH, G. G. The measurement of observer agreement for categorical data. Biometrics, v. 33, n. 1, p. 159-174, 1977. 
LEHNER, B.; DÖLL, P. Development and validation of a global database of lakes, reservoirs and wetlands. Journal of Hydrology, v. 296, p. 1-22, 2004.

LILLESAND, T. M.; KIEFER, R. W.; CHIPAN, J. W. Remote Sensing and Interpretation. 5. ed. Madison: Wiley, 2004. 763 p.

MITRA, S.; WASSMANN, R.; VLEK, P. L. G. An appraisal of global wetland area and its organic carbon stock. Current Science, v. 88, p. 25-35, 2005.

MEIRELLES, M. L.; FERREIRA, E. A. B.; FRANCO, A. C. Dinâmica Sazonal do Carbono em Campo Úmido do Cerrado. (Série Documentos, 164) Planaltina: Embrapa Cerrados, 2006. 29 p.

MELACK, J. M; HESS, L. L. Remote sensing of wetlands on a global scale. SIL News, v. 42, p. 1-5, 2004.
NOVO, E. M. L. M.; SHIMABUKURO, Y. E.; MERTES, L. O rio Amazonas em mosaico. Ciência Hoje, v. 24, n. 144, p. 59-61, 1998.

RATTER, J. A.; RIBEIRO, J. F.; BRIDGEWATER, $\mathrm{S}$. The Brazilian Cerrado vegetation and threats to its biodiversity. Annals of Botany, v. 80, p. 223-230, 1997.

RIBEIRO, J. F.; WALTER, B. M. T. Fitofisionomias do bioma Cerrado. In: SANO, S. M.; ALMEIDA, S. P. (Eds.). Cerrado: Ambiente e Flora. Embrapa Cerrados, p. 86-166, 1998.

YAVITT, J. B. Carbon dynamics in Appalachian peatlands of west Virginia and western Maryland. Water, Air and Soil pollution, v. 77, p. 271-290, 1994. 